\title{
Optimizing Investment Selection for PPP Framework in the Transport Sector: A Risk Perspective
}

\author{
Nguyen Minh Nhat ${ }^{1, *}$, Le Anh Dung ${ }^{2}$ \\ ${ }^{1}$ Institute of International Training and Cooperation, Hanoi Architectural University, Hanoi, Vietnam \\ ${ }^{2}$ Technology and Construction Organization Subject, Hanoi Architectural University, Hanoi, Vietnam
}

Received April 7, 2021; Revised May 18, 2021; Accepted June 15, 2021

\begin{abstract}
Cite This Paper in the following Citation Styles
(a): [1] Nguyen Minh Nhat, Le Anh Dung, "Optimizing Investment Selection for PPP Framework in the Transport Sector: A Risk Perspective," Civil Engineering and Architecture, Vol. 9, No. 4, pp. 1170-1178, 2021. DOI: 10.13189/cea.2021.090418.
\end{abstract}

(b): Nguyen Minh Nhat, Le Anh Dung (2021). Optimizing Investment Selection for PPP Framework in the Transport Sector: A Risk Perspective. Civil Engineering and Architecture, 9(4), 1170-1178. DOI: 10.13189/cea.2021.090418.

Copyright $\bigcirc 2021$ by authors, all rights reserved. Authors agree that this article remains permanently open access under the terms of the Creative Commons Attribution License 4.0 International License

\begin{abstract}
The huge financial requirement of essential transport infrastructure system has challenged the availability of government funding. To fill the fiscal gap, public-private partnerships (PPP) framework has been applied as a promising mechanism. The success of PPP projects, however, is significantly influenced by a number of critical factors. Therefore, an optimum and comprehensive evaluation of projects, reflecting critical risks, supporting investment decisions, has been highly demanded by both the public and private sector. Various works, in previous studies, have been spreading scientific models assessing risks in the construction industry, and some of them focused on the area of PPP. However, the majority of published methods just concentrated on addressing and leveling risks, and there is a lack of application in evaluating and comparing different PPP projects, as investment options, with regards to key issues. Hence, in the situation of limited budget, the public and private partners may struggle with deciding the most potential alternative. To overcome this real-world challenge, this paper, by proposing a mathematical model, attempts to optimize investment selection by evaluating different projects' riskiness with the focus on transport projects. Different actual PPP transport projects in Vietnam were employed as case studies to analyze the practicality of the proposed application.
\end{abstract}

Keywords Decision Making, Public-Private Partnership, Investment Optimization, Risk Management

\section{Introduction}

Developing countries, especially in Asia, have experienced rapid economic development in recent years which has increased the demand for investment in infrastructure systems. However, the massive need to deliver transport infrastructure has put a strain on government budget. Consequently, PPPs are becoming inevitable. The success of PPP projects, however, is significantly influenced by a number of critical factors. Therefore, an optimum and comprehensive evaluation of projects, reflecting critical issues, to make investment decision, has been highly demanded by both the public and private sector. Identification of critical could be processed. However, decision makers may struggle with the overlap of benefits and drawbacks associated with key factors [6].

Approaches and techniques to resolve difficulties in assessing benefits and drawbacks of influential factors have been researched in a number of academic and practical works. Take research by Lee et al. [10] as an example, the theory of planned behaviour was developed to build a system supporting strategy makers in the area of real estate. Lee et al. attempted to clarify strategies suggested in Alternative Dispute Resolution (ADR) prototype by addressing the deficiency associated with a conceptual core. With more focus on a specific stage of the project life cycle, support vector form and elimination regression are utilized by Sonmez and Sözgen [22] to create strategies in the bidding process. Their system demonstrates the improvement as the number of input 
factors required is reduced. This, in fact, enhances the generalizing process which proves significance in comparison to other frameworks applying linear regression and neural system. Evaluating previous academic and practical attempt in examining construction projects, Shevchenko et al. [20] emphasized that the multi-factor assessment including comprehensive qualitative analysis is essential. To support their statement, authors established an approach based on qualitative measurement weighing critical issues and influential factors, to suggest mitigation strategies.

In the literature of theories behind evaluation frameworks, Analytic Hierarchy Process (AHP), which is a multiple criteria decision-making technique, could be seen as a well-recognized model employed in numerous fields. This theory has been also applied to the construction industry. The theory was structured by Saaty [19] to convert subjective and linguistic evaluations to mathematical values by building pairwise comparisons between alternatives with regarding key criteria identified. Computed mathematical values build the foundation for decision makers to evaluate different options. One of the primary academic works adopting Saaty's theory to the construction industry was the research by Skibniewski and Chao [21]. Criticizing that traditional evaluation methods are unable to assess some aspects of specific projects, they attempted to remove the barriers in quantifying intangible features and risks connected with advanced building technologies. AHP was used to compare different intangible benefits and drawbacks of specific building technologies. Skibniewski and Chao also highlighted values of their framework compared to the conventional approach, which mainly focuses on economic features of the alternatives.

Exploring more particular areas of the construction industry, Analytic Hierarchy Process has been developed to manage key risks in PPP construction projects. For instance, the optimal proposal of a BOT contract for an individual construction can be highlighted using the AHP based-framework structuring a hierarchy of success drivers, built by Ababutain [1]. AHP application also proves its advantages in the research carried out by Zou et al. [27]. Authors observe that large and long investments in PPPs generate distinctive and dynamic issues which may not be sufficiently identified by conventional methods. Fuzzy sets are integrated into AHP system to identify and examine associated significant hazards through the project's life cycle. The integration of Fuzzy theory in their model is to reduce the risk of imprecise and uncertain data including crisp assessment. Compared to original AHP, Zou et al. model requires additional mathematical stage functioning defuzzification of fuzzy values. However, the high number of risk groups in their model may increase the inconsistency of judgment as Li et al. [11] suggested that the number of criteria in each layer should not be greater than five. Besides, defuzzification of fuzzy values to obtain risk weightings may lessen the fundamental benefits of AHP which is to evaluate options with respect to all critical criteria.

Literature review reveals that a number of studies applied mathematical methods to the construction industry, and some of them attempted to apply in the area of PPP. However, the majority of published methods just concentrated on addressing and levelling risks, and there is a lack of application in comparing different PPP projects with focus on the transport sector, as investment options, with regards to key issues. Hence, in the situation of limited budget, the public and private partners may struggle with deciding the most potential alternative. Besides, previous methods have been considered as difficult to use in real practice [20]. To overcome this real-world challenge, this paper attempts to utilize original AHP in conjunction with Computation of risk score to reinforce investment selection by comparing the riskiness of different projects, concerning critical risks associated. Evaluation resulting from this developed model could be extremely valuable for both sectors in examining different options regarding risk perspectives. Different actual PPP transport projects in Vietnam are employed as case studies to analyse the practicality of the proposed application.

\section{The Proposed Model}

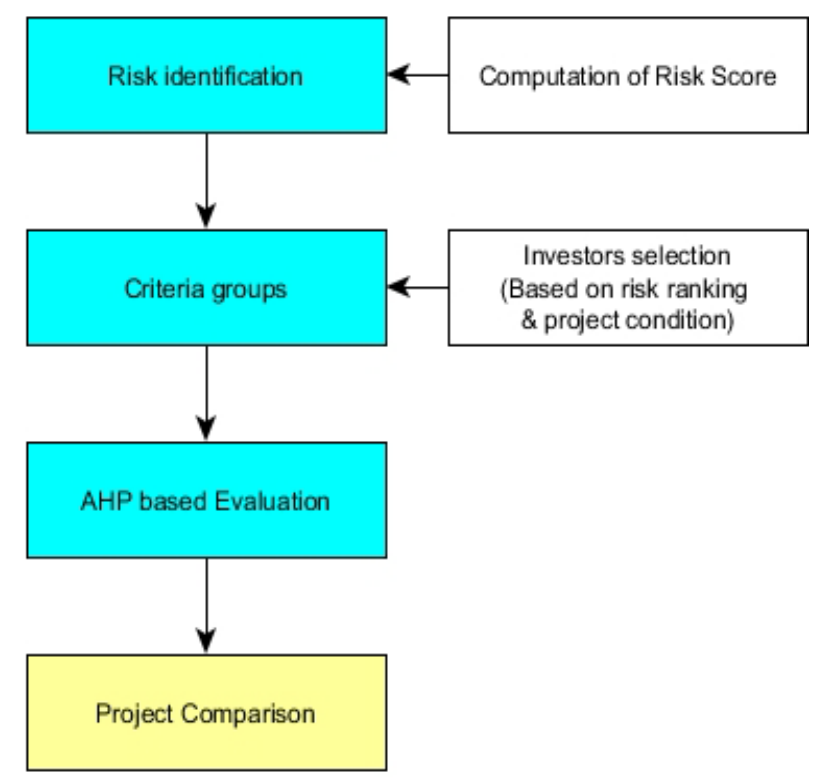

Figure 1. Process of Project Evaluation

\subsection{Computation of Risk Score}

Critical issues are analysed regarding their possibility of existence and the level of effect. Evaluations from experts are transferred to numeric inputs. Possibility of existence and the level of effect are evaluated based on 5 -scale grade, namely $0.9,0.7,0.5,0.3$, and 0.1 . These numbers present for the judgments of "very high", "high", "medium", "low", and "very low", respectively. 
Risk score can be computed as:

$$
R_{j}^{i}=P o_{j}^{i} \times E f_{j}^{i}
$$

$P o_{j}^{i}$ : Possibility of existence of risk i evaluated by expert j.

$E f_{j}^{i}$ : Level of effect of risk i evaluated by expert $\mathrm{j}$.

$$
R^{i}=\frac{\sum_{j=1}^{n} R_{j}^{i}}{n}
$$

$n$ : Number of experts participated.

Mean value ranking of scores presents the critical level of the risks. In this paper, the importance of different participants is treated equally as $[23,12]$ concluded that there is no clear proof of significant difference between results using weighted and non-weighted input for different participants. The level of distance from the value to the mean is figured using Standard Deviation $[5,8,16]$.

\subsection{AHP-based Investment Selection}

Optimal investment is selected based on pairwise comparison amongst options which, in this research, are different projects. Application of AHP allows evaluators to numerically rank alternatives based on comprehensive groups of critical issues. The configuration is demonstrated in Figure 2, and the detail of the proposed evaluation process is highlighted in Figure 3.

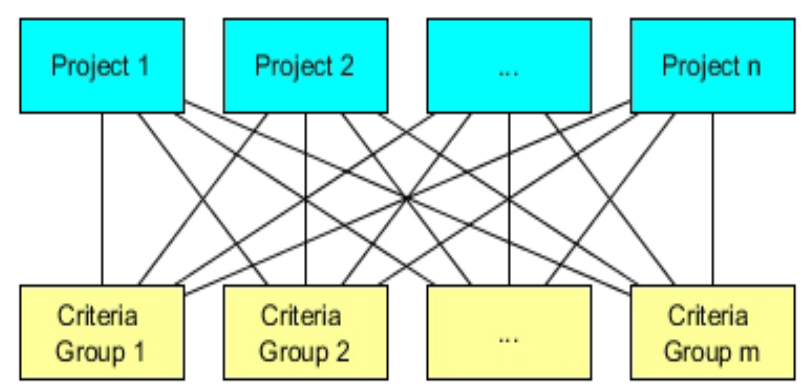

Figure 2. AHP structure in option evaluation

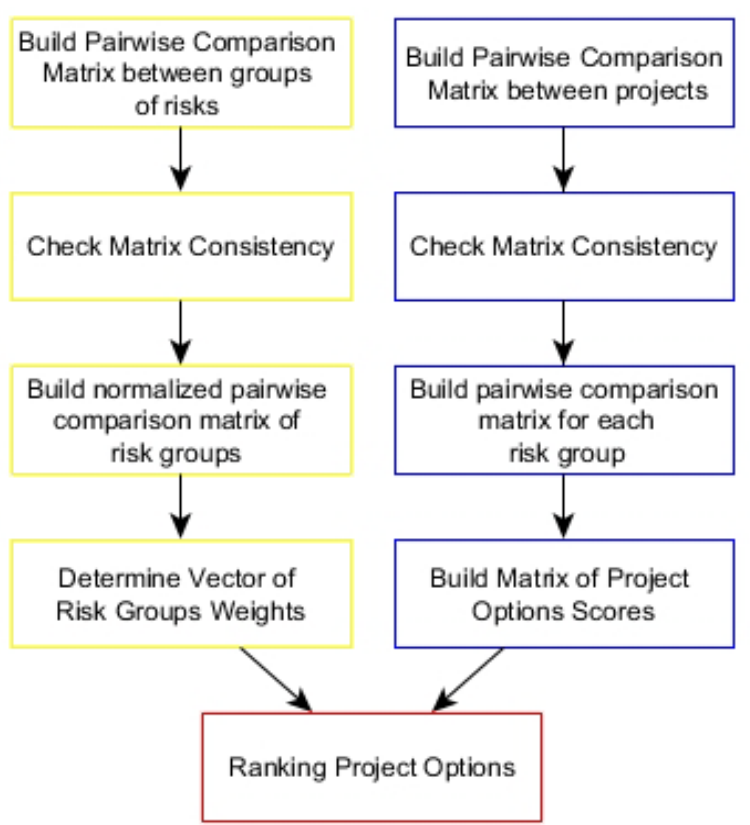

Figure 3. Process of evaluation

\subsubsection{Vector of Risk Group Weights}

Risks are categorized into $n$ groups. A is an $n \times n$ matrix built according to pairwise comparison amongst $n$ groups.

$$
\mathrm{A}=\left[\begin{array}{cccc}
1 & a_{12} & \ldots & a_{1 n} \\
a_{21} & 2 & \ldots & a_{2 n} \\
\ldots & \ldots & \ldots & \ldots \\
a_{n 1} & a_{n 2} & \ldots & 1
\end{array}\right]
$$

$a_{i j}$ signifies the significance of risk group $i$ compared to risk group $j$. The group $i$ is more significant than $j$ if the value of $a_{i j}$ is greater than 1 , and vice versa. It should be noted that $a_{i j} \times a_{j i}=1$. The significance comparison is assessed according to scales indicated in table 1 .

Table 1. Description of judgment

\begin{tabular}{|c|c|}
\hline $\begin{array}{c}\text { Numeric } \\
\text { Input }\end{array}$ & Description \\
\hline 1 & Two groups are equally significant. \\
\hline 3 & One group is slightly more significant. \\
\hline 5 & One group is strongly more significant. \\
\hline 7 & One group is very strongly more significant. \\
\hline 9 & One group is extremely more significant. \\
\hline
\end{tabular}

Table 2. Structure of comparison between groups

\begin{tabular}{|c|c|c|c|c|}
\hline & Group 1 & Group 2 & $\ldots$ & Group n \\
\hline Group 1 & 1 & & & \\
\hline Group 2 & & 1 & & \\
\hline$\ldots$ & & & 1 & \\
\hline Group n & & & & 1 \\
\hline
\end{tabular}


The significance judgment of different groups and structure of comparison are demonstrated in table 2 and 3. From these tables, the number of comparisons computed can be calculated as $\frac{\mathrm{n}(\mathrm{n}-1)}{2}$ for the risk groups and $\frac{\mathrm{m}(\mathrm{m}-1)}{2}$ for investment options.

Table 3. Structure of comparison between investment options

\begin{tabular}{|c|c|c|c|c|}
\hline & $\begin{array}{c}\text { Investment } \\
\text { option 1 }\end{array}$ & $\begin{array}{c}\text { Investment } \\
\text { option 2 }\end{array}$ & $\cdots$ & $\begin{array}{c}\text { Investment } \\
\text { option m }\end{array}$ \\
\hline $\begin{array}{c}\text { Investment } \\
\text { option 1 }\end{array}$ & 1 & 1 & & \\
\hline $\begin{array}{c}\text { Investment } \\
\text { option 2 }\end{array}$ & & & 1 & \\
\hline$\ldots$ & & & & 1 \\
\hline $\begin{array}{c}\text { Investment } \\
\text { option m }\end{array}$ & & & & \\
\hline
\end{tabular}

Using matrix A, the criteria weight vector is figured:

$$
\mathrm{W}=\left(\begin{array}{c}
\mathrm{w}_{1} \\
\mathrm{w}_{2} \\
\mathrm{w}_{3} \\
\cdots \\
\mathrm{w}_{5}
\end{array}\right)
$$

Where:

$$
\begin{aligned}
& w_{i}=\frac{\sum_{\mathrm{j}=1}^{\mathrm{m}} \overline{\mathrm{a}}_{\mathrm{ij}}}{\mathrm{m}} \\
& \overline{\mathrm{a}}_{\boldsymbol{i} \boldsymbol{j}}=\frac{\boldsymbol{a}_{\boldsymbol{i j}}}{\sum_{\boldsymbol{h}=\mathbf{1}}^{m} \boldsymbol{a}_{\boldsymbol{h}}}
\end{aligned}
$$

More specifically, each member $\mathrm{w}_{\mathrm{j}}$ of the vector $\mathrm{W}$ is found by finding the mean of each row in a new matrix which is built using members from matrix A, based on (5) and (6).

\subsubsection{Matrix of Option Score}

Each member of the matrix of the option displays the grade of option $i_{t h}$ regarding criteria (risk) $j_{t h}$.

To identify the matrix of option score, the matrix $\mathrm{B}^{\mathrm{j}}$, an $\mathrm{m} \times \mathrm{m}$ matrix with $\mathrm{m}$ is the number of investment option, needs to be built:

$$
\mathrm{B}^{(\mathrm{j})}=\left[\begin{array}{cccc}
b_{11}^{j} & b_{12}^{j} & \ldots & b_{1 n}^{j} \\
b_{21}^{j} & b_{22}^{j} & \ldots & b_{2 n}^{j} \\
\cdots & \ldots & \ldots & \ldots \\
b_{n 1}^{j} & b_{n 1}^{j} & \ldots & 1
\end{array}\right]
$$

Where $b_{i k}^{j}$ displays the judgment of investment option $k$ compared to investment option $j$, regarding the significance of criteria $j$.

$$
b_{i k}^{j} \times b_{k i}^{j}=1
$$

Matrix $\mathrm{B}$ is used to determine the matrix of option score $(\mathrm{O})$ using the similar method of forming the vector of risk group weights presented in (5) and (6).

$$
\mathrm{O}=\left[\mathrm{O}_{1}, \mathrm{O}_{2}, \ldots, \mathrm{O}_{\mathrm{m}}\right]
$$

\subsubsection{Investment Option Ranking}

The ranking of investment options is discovered by forming the vector I, where:

$$
\mathrm{I}=\mathrm{O} . \mathrm{W}
$$

Data in vector I presents the score of each investment option, regarding criteria (risks), and the ranking of these values validates the riskiness level of the alternative options.

\subsection{Data Experimentation}

To validate the applicability of the proposed model in PPPs, statistics from actual PPP transport projects were examined. At the first stage, the identification and ranking of critical risks in Vietnamese PPP market were discovered based on Computation of Risk Score. Table 4 below demonstrates a list of risks, categorized by different groups, namely, Construction, Legal, Market, Operation,

\begin{tabular}{|c|c|c|}
\hline Group & Code & Risk \\
\hline \multirow{4}{*}{ Construction } & Co1 & Unqualified product quality. \\
\hline & $\mathrm{Co} 2$ & Insufficient site safety. \\
\hline & $\mathrm{Co} 3$ & Land acquisition and relocation. \\
\hline & $\mathrm{Co} 4$ & Unrealistic feasibility study. \\
\hline \multirow{5}{*}{ Legal } & Le1 & Lack of guarantees by the authority \\
\hline & Le2 & Project approval process. \\
\hline & Le3 & Law changes. \\
\hline & Le4 & Tariff Restriction. \\
\hline & Le5 & Taxation Uncertainty. \\
\hline \multirow{4}{*}{ Market } & Ma1 & Low transparency. \\
\hline & Ma2 & $\begin{array}{c}\text { Insufficient fiscal capacity of } \\
\text { investor }\end{array}$ \\
\hline & Ma3 & Inflation rate variation. \\
\hline & $\mathrm{Ma} 4$ & Interest rate variation. \\
\hline \multirow{4}{*}{ Operation } & Op1 & High operation cost. \\
\hline & $\mathrm{Op} 2$ & Low operation quality. \\
\hline & $\mathrm{Op} 3$ & High Maintenance cost. \\
\hline & Op4 & Demand Fluctuation. \\
\hline \multirow{2}{*}{ Political } & Po1 & Concession termination. \\
\hline & Po2 & Corruption and bribery. \\
\hline \multirow[b]{2}{*}{ Relationship } & Re1 & Inappropriate risk allocation. \\
\hline & $\operatorname{Re} 2$ & $\begin{array}{l}\text { Low quality cooperation between } \\
\text { parties. }\end{array}$ \\
\hline Other & Oth & Negative nature events. \\
\hline
\end{tabular}
Political and Relationship Risks, based on in-depth literature review. Experts on the field are invited to evaluate these risks, according to the actual condition of the market, in terms of the possibility of existence and the level of effect.

Table 4. Risk groups 
In the next steps, in order to apply AHP-based system, a set of options and a set of criteria are established. In terms of criteria, 10 critical risks from table 4 were chosen by investors to set up criteria groups. Investors are required to decide critical issues, based on the risk scores computed and real condition of the actual projects selected, to set criteria groups demonstrated in table 5 .

With the purpose of evaluating different projects, 5 actual PPP transport projects, including 4 bridge projects and 1 highway project, are used as alternative investment options. In this paper, projects are named Project 1, Project 2, Project 3, Project 4, and Project 5. They are large scales projects in the transport sector in Vietnam and have been highly criticized for critical risks associated. Projects are pairwise compared and linguistic measures are transferred into numbers following expression in table 1 to create the Matrix of option scores based on (4), (5), (6), (7) and (8).

\section{Results and Discussion}

The result of risk scores is demonstrated in table 5 . These statistics reflect the general situation of Vietnamese PPP market in the transport sector. It can be seen that the most critical risks spread into all groups, excepting the relationship category.

Table 5. Ranking of risks in PPP project

\begin{tabular}{|c|c|c|c|c|c|}
\hline \multirow{2}{*}{ Code } & \multirow{2}{*}{ Risks } & \multicolumn{4}{|c|}{ General } \\
\hline & & Score & Rating & St. deviation & P-value \\
\hline $\mathrm{Co} 3$ & Land acquisition and relocation & 0.502 & 1 & 0.121 & 0.551 \\
\hline Le3 & Project approval process & 0.463 & 2 & 0.106 & 0.293 \\
\hline Ma3 & Inflation rate variation & 0.403 & 3 & 0.122 & 0.000 \\
\hline Op3 & High Maintenance cost & 0.374 & 4 & 0.098 & 0.962 \\
\hline Po2 & Corruption and bribery & 0.373 & 5 & 0.132 & 0.881 \\
\hline Op4 & Demand Fluctuation & 0.342 & 6 & 0.111 & 0.00 \\
\hline Ma2 & Insufficient fiscal capacity of investor & 0.337 & 7 & 0.105 & 0.018 \\
\hline Ma1 & Low transparency & 0.336 & 8 & 0.101 & 0.149 \\
\hline $\mathrm{Co} 2$ & Insufficient site safety & 0.324 & 9 & 0.112 & 0.000 \\
\hline Le5 & Tariff Restriction & 0.318 & 10 & 0.107 & 0.032 \\
\hline Ma4 & Interest rate variation & 0.314 & 11 & 0.107 & 0.000 \\
\hline $\mathrm{Co} 1$ & Unqualified Product quality & 0.310 & 12 & 0.100 & 0.002 \\
\hline $\mathrm{Co} 4$ & Unrealistic feasibility study & 0.291 & 13 & 0.086 & 0.015 \\
\hline Po1 & Concession termination & 0.268 & 14 & 0.084 & 0.000 \\
\hline Le1 & Lack of guarantees by the authority & 0.264 & 15 & 0.096 & 0.000 \\
\hline $\operatorname{Re} 2$ & Low quality Cooperation between parties & 0.258 & 16 & 0.089 & 0.000 \\
\hline Le4 & Law change & 0.244 & 17 & 0.126 & 0.000 \\
\hline Re1 & Inappropriate risk allocation & 0.229 & 18 & 0.143 & 0.000 \\
\hline Le6 & Taxation Uncertainty & 0.184 & 19 & 0.082 & 0.000 \\
\hline Op1 & High Operation cost & 0.174 & 20 & 0.103 & 0.000 \\
\hline Oth & Negative nature events & 0.172 & 21 & 0.064 & 0.055 \\
\hline Op2 & Low operation quality & 0.151 & 22 & 0.006 & 0.002 \\
\hline
\end{tabular}


Amongst most critical subjects presented, Land acquisition and relocation (Co3), Project Approval Process (Le3), and Demand Fluctuation (Op4), and Financial capacity of investor (Ma2) are most emphasized by expert groups, although some of these issues did not present highest statistics. More specifically, Co3 is the most serious hazard. This finding is consistent with previous studies' results such as $[24,9]$ indicating that $\mathrm{Co} 3$ is one of the most worrying issues in Vietnamese construction plans. Co3 occurs as the demand of landowners is not satisfied during the acquisition and resettlement process. The conflicts contain financial issues and the living standard requirements in the resettled habitat. Project Approval Process (Le3) displays the concerns where the timing schedule does not follow the plan. The excessive approval process is evaluated as a result of the complex and multi-layers of the authorities. Reddy [18] clarified that multi-layers of the authorities create multiple approvals requiring too many documents which make approval process time consuming. Le3 can, in fact, change the project financial plan as variables fluctuate during the long lasting process [15]. Seriously, participants stated that Le3 seems to be external to investors. Demand Fluctuation (Op4) is the risk strongly emphasized by participants from both parties. Op4, in fact, is the critical issue for all PPPs in the transport sector [14]. The shortfall in demand can lead to a default of related partners. International experience in developing countries has shown similarity concerns as this reduction can be $48 \%$ compared to estimated level [7,3]. Despite the fact that longer contract can be applied for specific reasons of shortfall, an extensive agreement brings other disadvantages, such as uncertainties and additional costs. Financial capacity of investor (Ma2) refers to the situation where investors' financial ability is inadequate for building and operating infrastructure. The loopholes in defining investor's financial capacity can come from incautious evaluation of financial reports and of projects in which financiers are invested in. Apart from above briefly analysed risks, other subjects and data in table 5 provide more insights of issues required to cautiously consider in making investment decision.

Based on risk ranking and the actual condition of five selected PPP projects, experts are required to form a set of criteria demonstrated in table 6 . In this paper, the set of criteria is structured to spread all risk groups. This structure is expected to create the comprehensive evaluation regarding all aspects of projects. However, it should be noted that in practice, decision makers can choose a different number of risks as well as the categories for a specific target.
Table 6. Set of criteria

\begin{tabular}{|c|c|}
\hline Group & Risk \\
\hline \multirow{2}{*}{ Construction } & Co1. Unqualified Product quality. \\
\cline { 2 - 2 } & Co3. Land acquisition and relocation. \\
\hline $\begin{array}{c}\text { Political and } \\
\text { legal }\end{array}$ & Le3. Project approval process. \\
\cline { 2 - 2 } Market & Po2. Corruption and bribery. \\
\cline { 2 - 2 } & Ma2. Financial capacity of investor. \\
\hline \multirow{2}{*}{ Operational } & Ma3. Inflation rate variation. \\
\cline { 2 - 2 } & Op1. High Operation cost. \\
\hline \multirow{2}{*}{ Relationship } & Op3. High Maintenance cost. \\
\cline { 2 - 2 } & Re1. Inappropriate risk allocation. \\
\hline
\end{tabular}

By setting up 5 groups of criteria, the number of pairwise comparison in the proposed framework is lowered to fit the scale of the current research. This is a strongly important point as the level of inconsistency is reduced and the time of analysing process is shortened.

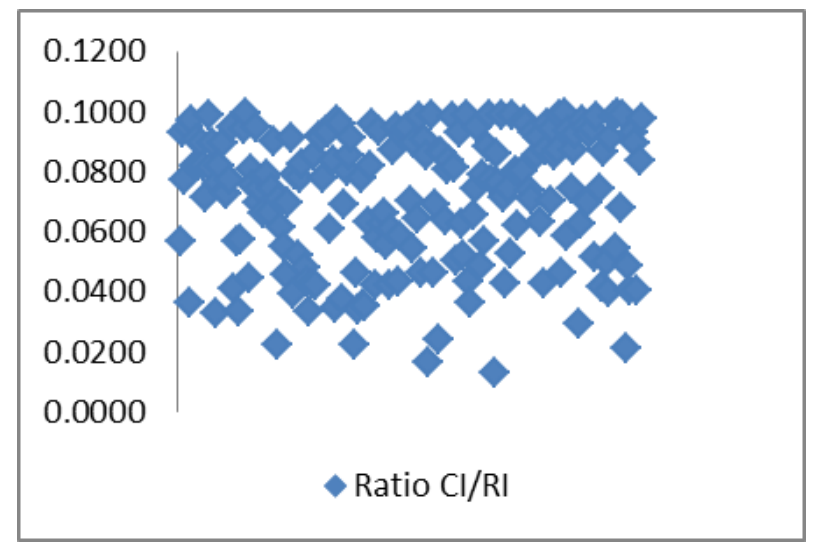

Figure 4. Ratio of consistent matrices

The ratio of consistent statistic is displayed in figure 4 . The matrix with lower ratio is measured as higher consistent, and a matrix is used if its ratio is not greater than 1. Inconsistent information was eliminated and the input for AHP system was only based on consistent statistics. In fact, the theory of AHP allows a certain level of variation as human is not consistent at all-time [18].

\subsection{Vector of Criteria Weights (w)}

From the data input, AHP system employs (4), (5), (6) to form the Vector of Criteria Weights (W):

$$
\mathrm{W}=\left(\begin{array}{c}
\text { Construction } \\
\text { Political and legal } \\
\text { Market } \\
\text { Operational } \\
\text { Relationship }
\end{array}\right)\left(\begin{array}{c}
0.276 \\
0.199 \\
0.136 \\
0.268 \\
0.118
\end{array}\right)
$$


This vector describes that according to analyzers, in five selected projects, Construction risks, containing Unqualified Product quality Land acquisition and reallocation, are the most critical issues. Operation risks, including High Operation cost, High Maintenance cost, are positioned at the second position while Operational risks are evaluated as the least critical compared to other groups. This ranking meaning is different compared to ranking in table 4 . While table 4 shows the general ranking regarding the market, the Vector of Criteria Weights demonstrates the weights of risk groups in the context of five specified projects selected.

\subsection{Matrix of Option Scores}

Similarly, using data collected and computing method described, the Matrix of Option Scores (O) is determined as:

$$
\mathrm{O}=\left(\begin{array}{rrrrr}
0.152 & 0.251 & 0.102 & 0.289 & 0.226 \\
0.080 & 0.366 & 0.058 & 0.403 & 0.288 \\
0.240 & 0.188 & 0.403 & 0.067 & 0.153 \\
0.264 & 0.115 & 0.291 & 0.167 & 0.198 \\
0.262 & 0.078 & 0.144 & 0.071 & 0.134
\end{array}\right)
$$

This matrix describes pairwise comparison between investment options (five actual projects) regarding each risk group, using (7), (8), (9). In order to find the comparison of options regarding all risk groups, Investment Option Ranking vector I is shown below.

\subsection{Investment Option Ranking}

Using (10), the ranking of investment options is presented in table 7 .

Table 7. Project option ranking regarding associated risks

\begin{tabular}{|c|c|c|}
\hline Score & Investment options & Ranking \\
\hline 0.211 & Project 1 & 2 \\
\hline 0.246 & Project 2 & 1 \\
\hline 0.195 & Project 5 & 4 \\
\hline 0.204 & Project 4 & 3 \\
\hline 0.143 & Project 3 & 5 \\
\hline
\end{tabular}

Table 7 presents the riskiness level of different investment options. Statistic shows that project 2 is the riskiest alternative whereas project 3 is evaluated as the safest investment option. Values presented for project 1, project 2 and project 3 show smaller differences compared to the riskiness level of project 3. In reality, further evaluation of projects with a significant difference of riskiness level can be carried out.

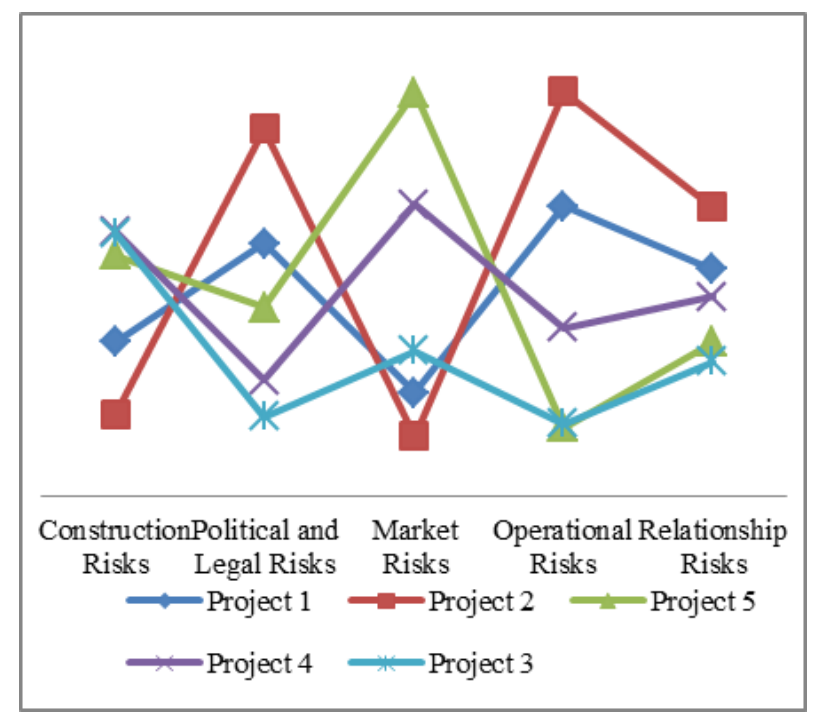

Figure 5. Graphical representation of options' riskiness ranking

Table 7 and Figure 5 highlight the value of the proposed model in comparing alternatives. If a qualitative investigation was conducted only, decision makers may struggle with the overlap of benefits and drawbacks associated with each option. The comparison, therefore, may not be conclusive. With AHP and Computation of risk score, the proposed model transferred linguistic judgment to statistic comparison. Using graphical representation presented in Figure 5, investors will be able to have a quantitative evaluation of potential alternatives, not only in terms of the comprehensive riskiness but also with respect to each risk group. For instance, regarding Market risks, project 5 is the riskiest while in terms of Operational group, it is the least risky investment option.

Fundamental ideas of AHP in this paper are, to some extent, similar to previous research such as $[12,17]$. However, the structure of the system is different. While $[12,17]$ utilize AHP to detect key risks, the model in this research is to compare the riskiness of different projects. Identification of critical risks is, instead, conducted using Computation of risks score. This, indeed, reduced the level of complexity of the system. Besides, the number of criteria in each level of AHP system in $[12,17]$ was high compared to the optimal statistic suggested by researchers [11]. The structure of AHP system in this paper is also significantly different from frameworks created by Zhang and Zou [26], Chang and Liu [4]. The difference is created as a result of the unique target. While $[26,4]$ employed AHP select proposal in different plans of one specific project, the model proposed in this paper is to select optimal investment option amongst different alternatives. Level of inconsistency may be reduced in research by $[26$, 4] by using integrated Fuzzy system. Nevertheless, the complexity of the system is certainly increased. The problem of inconsistent information, in this paper, is diminished by using the computation of risk score. This integration also provides evaluators with more insights 
into critical threats during the process of forming the criteria set.

\section{Conclusions and Future Research}

This paper clarifies a mathematical model to optimize investment selection for PPP transport projects. The application of AHP in conjunction with Computation of Risk Score in evaluating of different PPP transport projects, as investment options, has not been done in earlier studies. In practice, optimization of investment selection is especially beneficial as its ability to support both sectors in defining the least risky investment options to implement in the PPP mechanism.

Based on AHP and Computation of Risk Score, a scheme was developed and five actual PPP transport projects were employed to demonstrate the proposed method. The results proved that the applied process can provide public and private partners not only with the scientific evaluation of the investment option's riskiness regarding comprehensive hazards but also the comparison of options' riskiness concerning each criteria category. It is worth pointing out that the number of risk groups and the number of risks in each group can be modified in reality based on the aspects that associated partners wish to investigate.

This proposed application, however, also contains its limitation. More specifically, AHP should be more efficient if the number of criteria (or sub-criteria) is not over five. This means the number of risks evaluated should not be over 25 risks divided into 5 groups. This might limit the number of risks in each level of the hierarchy structure. In order to overcome this limitation, selection of critical risks to create criteria group must be cautiously carried out. Future research may explore the limitation of this paper by developing a mechanism which is capable of analysing a higher number of risks by reducing inconsistent of AHP without increasing complexity of the evaluation system.

\section{Acknowledgments}

We are very grateful to experts for their involvement in this research both in terms of industry analysis and model development.

\section{REFERENCES}

[1] Ababutain A. Y. A multi-criteria decision-making model for selection of bot toll road proposals within the public sector, Doctoral dissertation, University of Pittsburgh, 2002.
[2] Bhushan N., Rai K. Strategic Decision Making: Applying the Analytic Hierarchy Process, Springer-Verlag London, 2004.

[3] Carpintero, S., O. H. Petersen. PPP projects in transport: Evidence from light rail projects in Spain. Public Money Manage, Vol. 34, No. 1, 43-50, 2014, https://doi.org/10.1080/09540962.2014.865935.

[4] Chang, M and Liu, W. Study on the Selection Method of PPP Mode in the Domain of Public Infrastructure, International Journal of Business and Management, Vol. 3, No. 4, 100-106, 2008

[5] Christmann, A., Aelst S. V. Robust estimation of Cronbach's alpha, Journal of Multivariate Analysis, Vol. 97, No. 7, 1660-1674, 2006. https://doi.org/10.1016/j.jmva.20 05.05 .012

[6] Issa U. H., Ahmed A., Ugai K. A Decision Support System for Ground Improvement Projects Using Gypsum Waste Case Study: Embankments Construction in Japan, Civil and Environmental Research, Vol. 3, No. 3, 74-84, 2013. https://core.ac.uk/download/pdf/234677665.pdf

[7] Kiggundu, A. Financing public transport systems in Kuala Lumpur, Malaysia: Challenges and prospects, Transportation, 36 (3), 275-294, 2009

[8] Kottner J., Streiner D. L. Internal consistency and Cronbach's $\alpha$ : A comment on Beeckman et al. (2010), International Journal of Nursing Studies, Vol. 47, No. 7, 926-928, 2010.http://dx.doi.org/10.1016/j.ijnurstu.2009.12 .018

[9] Le, N., Chong, W. O. Sullivan, Kenneth. Construction Risks in Developing Countries: A Vietnam Case Study, Journal for the Advancement of Performance Information and Value, Vol. 2, No. 1, 2020, DOI 10.37265/japiv.v12i1. 41

[10] Lee C. K., Yiu T. W., Cheung S. O. Selection and use of alternative dispute resolution (ADR) in construction projects. International Journal of Project Management, Vol. 34, Vo. 3, 494-507, 2016. https://doi.org/10.1016/j.ijprom an.2015.12.008

[11] Li F., Phoon K.K., Du. X., Zhang. Improved AHP Method and Its Application in Risk Identification, Journal of Construction Engineering and Management, Vol. 139, No. 3, 312-320, 2013. http://dx.doi.org/10.1061/(ASCE)CO.19 43-7862.0000605

[12] Li, J. and Zou, P. (2011). Fuzzy AHP-Based Risk Assessment Methodology for PPP Projects. J. Constr. Eng. Manage, Vol. 137, No. 12, 1205-1209

[13] Li J., Zou P. Risk Identification and Assessment in PPP Infrastructure Projects using Fuzzy Analytical Hierarchy Process and Life-Cycle Methodology, Australasian Journal Of Construction Economics And Building, Vol. 8, No. 1, 34-48, 2012. http://dx.doi.org/10.5130/ajceb.v8i1.2996

[14] Oliveira, M., Ribeiro, J., Macario, R. Are we planning investments to fail? Consequences of traffic forecast effects on PPP contracts: Portuguese and Brazilian cases, Research in Transportation Economics, 59, 167-174, 2016.

[15] Patrick, X.W., Zhang, Guomin., Wang, J. Identifying Key Risks in Construction Projects: Life Cycle and Stakeholder 
Perspectives, International Journal of Construction Management, Vol. 9, No. 1, 2014.

[16] Pinto F. S. T., Fogliatto F. S. Qannari E. M. A method for panelists' consistency assessment in sensory evaluations based on the Cronbach's alpha coefficient, Food Quality and Preference, Vol. 32, part A, 41-47, 2014. https://doi.org/10.1016/j.foodqual.2013.06.006

[17] Raisbeck, P., Tang, L.C.M. Identifying design development factors in Australian PPP projects using an AHP framework, Construction Management and Economics, Vol. 31, No. 1, 20-39, 2013

[18] Reddy, H. L., Nagakumar, M. S., Swathi, H. Impact Assessment and Prioritization of Critical Delay Factors for a Road Project, Civil Engineering and Architecture, Vol. 8, No. 2, 1325-1334, 2020. https://doi.org/10.13189/cea.2020 .080616 .

[19] Saaty, T. L. The Analytic Hierarchy Process, McGraw - Hill, New York, 1980.

[20] Shevchenko G., Ustinovichius L., Walasek D. The evaluation of the contractor's risk in implementing the investment projects in construction by using the verbal analysis methods, Sustainability, Vol. 11, Vo. 9, 1-18, 2019. http://dx.doi.org/10.3390/su11092660

[21] Skibniewski M. J., and Chao L. C. Evaluation of Advanced Construction Technology with AHP Method, Journal of Construction Engineering and Management, Vol. 118, No. 3, 577-593, 1992. https://ascelibrary.org/doi/10.1061/\%28
ASCE\%290733-9364\%281992\%29118\%3A3\%28577\%29

[22] Sonmez R., Sözgen B. A support vector machine method for bid/no bid decision making, Journal of Civil Engineering and Management, Vol. 23, No. 5, 641-649, 2017. https://doi.org/10.3846/13923730.2017.1281836

[23] Thuyet N. V., Ogunlana S. O. Risk management in oil and gas construction projects in Vietnam, International Journal of Energy Sector Management, Vol. 1, No. 2, 175 - 194, 2007. http://dx.doi.org/10.1108/17506220710761582

[24] Ty, P. H., Van Westen, A. C.M., Zoomers, A. Compensation and Resettlement Policies after Compulsory Land Acquisition for Hydropower Development in Vietnam: Policy and Practice, Land, No. 2, 678-704, 2013; doi: 10.3390/land2040678

[25] Wang Y., Liu J., Elhag, T. M. S. An integrated AHP-DEA methodology for bridge risk assessment, Computer and Industrial Engineering, Vol. 54, No. 3, 513-525, 2008. https://doi.org/10.1016/j.cie.2007.09.002

[26] Zhang, G. and Zou, P. Fuzzy Analytical Hierarchy Process Risk Assessment Approach for Joint Venture Construction Projects in China, J. Constr. Eng. Manage, Vol. 133, No. 10, 771-779, 2007.

[27] Zou P., Wang S., Fang D. A life-cycle risk management framework for PPP infrastructure projects, Journal of Financial Management of Journal of Financial Management of Property and Construction, Vol. 13, No. 2, 123-142, 2008. http://dx.doi.org/10.1108/13664380810898131 